\title{
When the Furnace Goes On in a California Tract House · Ruth Stone
}

\author{
If the blower is on \\ you may experience otherness - \\ then the clear plastic saltshaker \\ with her wide bottom, sexy waist \\ and green plastic head, \\ her inner slope of free running crystals, \\ is visibly crumbling \\ in the sight of the frankly opaque pepper \\ who seems taller, even threatening, \\ though they are the same size, \\ in fact, a designed pair. \\ His contents are hotter. \\ "Yes," she sighs, "the pepper is strong. \\ How he asserts himself on the cream soup-" \\ Or, "What is an egg without his gesture?" \\ Little does she suspect in her ability to dissolve \\ without losing herself, that the very blood . . . \\ "It's degrading," she confides, "the way they pinch me."
}

